\title{
ENDEMICITY ANALYSIS OF GLOBAL CRETACEOUS DINOSAURIAN FAUNAS
}

HOLTZ*, Thomas R., Jr., U.S. Geological Survey, M.S. 970 National Center, Reston, VA 22092 U.S.A.

It has often been assumed that the intensively studied dinosaur faunal assemblages of western North America and the Gobi Desert of Mongolia and China represent "typical" Late Cretaceous terrestrial vertebrate communities. This assumption has led to a paleoecological scenario in which a global ecological shift occurs from the dominance of high-browsing saurischian (i.e., sauropod) to lowbrowsing ornithischian (i.e., iguanodontian, marginocephalian, ankylosaurian) herbivore communities. Furthermore, the assumption that the Asiamerican dinosaur faunas are communities "typical" of the Late Cretaceous has forced the conclusion that the sauropod-dominated Argentine population must have been an isolated relict ecosystem of primitive taxa (i.e., titanosaurid sauropods, abelisaurid ceratosaurs). Recent discoveries and reinterpretations of other Late Cretaceous assemblages, however, seriously challenge these assumptions.

Paleogeography and paleobiogeography have demonstrated that terrestrial landmasses became progressively fractionated from the Late Jurassic (KimmeridgianTithonian) to the Late Cretaceous (Campanian), owing to continental drift and the development of large epicontinental seas (the Western Interior Seaway, the Turgai Sea, etc.). The Maastrichtian regressions resulted in the reestablishment of land connection between long isolated regions (for example, western and eastern North America). These geographic changes are reflected in changes in the dinosaurian faunas. These assemblages were rather cosmopolitan in the Late Jurassic (Morrison, Tendaguru, and Upper Shaximiao Formations) but became more provincialized throughout the Cretaceous.

Cluster analysis of presence/absence data for the theropod, sauropod, and ornithischian clades indicates that previous assumptions for Late Cretaceous dinosaurian paleoecology are largely in error. These analyses instead suggest that sauropod lineages remained a major faunal component in both Laurasia (Europe, Asia) and Gondwana (South America, Africa, India, and Australia). Only the preMaastrichtian Senonian deposits of North America were lacking sauropodomorphs. Furthermore, the abelisaurid/titanosaurid fauna of Argentina is, in fact, probably more typical of Late Cretaceous dinosaurian communities. Rather, it is the coelurosaurian/ornithischian communities of Asiamerica (and particularly North America) that are composed primarily of dinosaurs of small geographic distribution. Thus, the Judithian, Edmontonian, and Lancian faunas, rather than being typical of the Late Cretaceous, most likely represent an isolated island-continent terrestrial vertebrate population, perhaps analogous to the extremely isolated vertebrate communities of Tertiary South America. Furthermore, the shift from high-browsing to low-browsing herbivore "dynasties" more likely represents a local event in Senonian North America and does not represent a global paleoecological transformation of Late Cretaceous dinosaur community structure. 